\title{
Must Expression Be Instrumental?
}

\author{
Stina Bäckström*
}

Received: 16 April 2019 / Revised: 4 November 2019 / Accepted: 2 December 2019

Abstract: This article engages critically with the theory of expression proposed by Mitchell Green in his Self-Expression (2007). In this book, Green argues that expressions are signals designed to convey information about mental states. By putting pressure on one of the examples Green uses in his book, I will challenge this thesis. I will then deepen this challenge by developing a contrast between two philosophical perspectives on expression, which I name the 'instrumental' and the 'descriptive'. I take Green's theory of expression to be an exemplar of the instrumental perspective. Expression, in the instrumental perspective, is a means for transmitting information about mental states from organism to organism. The descriptive perspective I articulate with the help of Maurice Merleau-Ponty and Ludwig Wittgenstein. On the descriptive view, expression is (at least a part of) an answer to the question what it is so much as to have mental states and a living body. I suggest at the end of the article that if we remain within the instrumental perspective, we will not be able to use expression to satisfactorily answer this question.

Keywords: Expression; Green; Merleau-Ponty; signal; Wittgenstein.

* Södertörn University

(i) https://orcid.org/0000-0002-1326-4844

- Centre for Practical Knowledge, Södertörn University Alfred Nobels allé 7 Flemingsberg 14189 Huddinge, Sweden

$\triangle$ stina.backstrom@sh.se

() The Author. Journal compilation (C) The Editorial Board, Organon F.

This article is distributed under the terms of the Creative Commons Attribution-NonCommercial 4.0 International Public License (CC BY-NC 4.0). 


\section{Introduction}

Our view of man will remain superficial so long as we do not return to this origin, so long as we do not rediscover the primordial silence beneath the noise of words, and as long as we do not describe the noise that breaks the silence. Speech is a gesture, and its signification is a world. (Merleau-Ponty, 2012 [1945], 190)

When Mitchell S. Green's book Self-Expression was published in 2007, I was setting out to write a dissertation on expression. At that stage of research, and that stage of one's career, a new book length treatment of one's subject - especially when such treatments are rare - is rather anxiety provoking. I knew I had to respond to the book, and I was afraid it would say everything I had wanted to say. This did not prove to be true, not the least because I did not, at that time, know what I wanted to say. What turned out to be the case was that Green's book shaped what I wanted to say. It gave me something - a theoretical vocabulary, a set of examples - to which to respond.

It has taken me a while (I am an untimely slow reader) to articulate what I found problematic about the perspective on expression the book offers. I have responded to specific parts of the book elsewhere, to moments and particular theses (see Bäckström 2013a; 2013b; 2016), but I haven’t been able to clearly position it, or myself with respect to it. This paper is an attempt to do so. I know Green's thinking has moved on in various interesting directions since then, but I hope he has not moved so far as to make my intervention here obsolete.

My primary aim in this article is to articulate a challenge to Green's thesis that an expression is a signal. I will do so by developing a contrast between two different perspectives on expression. ${ }^{1}$ The first I call the 'instrumental perspective'. Green's book is an exemplar of this perspective. What characterizes the instrumental perspective is that its guiding idea is

1 In calling them 'perspectives' rather than 'theories' I wish to indicate that the differences between them are not only or even primarily in the resulting account of expression but in the guiding questions and background assumptions. I want to say something about the place where they, respectively, start looking (as it were) for expression. 
that expression is a means for transmitting information about mental states from one organism to another. The instrumental perspective takes as its primary question how expression can carry information about mental states to other people.

The second perspective I articulate with the help of Maurice MerleauPonty's treatment of expression in Phenomenology of Perception, and a set of remarks from Ludwig Wittgenstein's Philosophical Investigations. I call it the 'descriptive perspective'. The descriptive perspective takes as its guiding idea that we need to understand expression in order to understand what it is to so much as have mental states and a living body. ${ }^{2}$ It understands expression to be essential to understanding the mode of being of human beings and other living creatures. As we will see, I take the different perspectives to differ not only in its guiding question (in how they approach expression) but also in substance (in what they understand expression to be). ${ }^{3}$

It might appear odd that I'm grouping Merleau-Ponty and Wittgenstein together under a common heading. Merleau-Ponty explicitly writes himself into the phenomenological tradition, whereas Wittgenstein doesn't. And there are important differences in their respective method and style. Perhaps there are also deep philosophical disagreements between them related to those differences in method and style. I think it is striking, however, when making the attempt at establishing a conversation between the two thinkers on the notion of expression (at least when staying with a comparison between The Phenomenology of Perception and The Philosophical Investigations) how they complement each other. ${ }^{4}$

2 I use the term 'mental states' mostly for convenience in this paper, in order to establish a conversation between the parties involved. It is not a term I am comfortable with, since it pulls us towards thinking in terms of a contrast between the mental and static one the one hand and the bodily and dynamic on the other. But it will do for the purposes of the dialectic in this paper.

3 The contrast between the perspectives will be rough in outline. In my experience, there is value in philosophy in alternating between zooming in and zooming out. The risk when zooming out, is of course that one rides roughshod over distinctions and loses sight of specificity.

4 The connection between Wittgenstein and various figures (most notably Heidegger) in the phenomenological tradition has been explored for a long time, but recently there appears to be a surge of interest specifically in comparing Merleau- 
It might appear odd, too, with a contrast between an instrumental perspective and a descriptive perspective. The descriptive is more commonly contrasted with the explanatory. But the contrast I am after here is not happily put in terms of a focus on what there is on the one hand and why it is on the other hand. Both Green and the proponents of the descriptive perspective are interested in what expression is. I use the notion of description here to indicate an interest both in the what and the is of "What is expression?" An interest in the $i s$ can be translated in terms of the question, "What is it for an expression to be?" This question, according to the descriptive perspective, cannot be asked without at the same time asking the question "What is it for mental states to be?" 5

Green's book is a philosophical theory of expression with a particular focus on understanding the continuity between non-linguistic expression and speech-acts. Green approaches expression from "evolutionary biology as informed by game-theory" (Green 2007, 16). Given this starting point, it might appear as if the two perspectives I am contrasting are simply too far apart for the comparison to be meaningful. Wittgenstein and MerleauPonty, each in different ways, think philosophical clarification needs to achieve some distance to the conceptual frameworks of scientific theories.

I think, however, that Green's theory of expression is an excellent articulation of a philosophical perspective on expression that has considerable

Ponty and Wittgenstein. For example, Avner Baz uses Wittgenstein and MerleauPonty alongside each other on the topic of perception and motivation in the article "Motivational Indeterminacy" (2017). And two anthologies have been published recently devoted partially or entirely to exploring the affinities between the thinkers: Wittgenstein and Merleau-Ponty (2017) and Wittgenstein and Phenomenology (2018).

5 I have struggled with the terminology and I am not completely happy with the current one. I have considered re-naming the descriptive perspective the 'phenomenological perspective'. This would have had the advantage of avoiding making it seem as if the instrumental perspective has no descriptive commitments or interests. And I think the question whether it is illuminating to describe Wittgenstein as a phenomenologist is a good one. But what I am after in this article is how MerleauPonty and Wittgenstein both think we need to re-think certain fundamental philosophical questions if we are to understand expression. To me, there is nothing distinctively phenomenological about this thought. 
appeal, and this appeal is not dependent on a particular investment in the conceptual framework of evolutionary biology. I think (and Merleau-Ponty and Wittgenstein also thought) that it is a natural enough idea that expression must fundamentally be understood as a means for making one's mental life public. Articulating why this natural idea is problematic, perhaps radically so, is - from their point of view and mine - a worthwhile project. Creating a dialogue between this contemporary exemplar and two philosophers in our recent history who took expression to be an eminently important philosophical concept will, my hope is, create an interesting dialectic.

Although my main aim is to articulate the perspectives by contrast with each other, I will also pose a challenge for the instrumental perspective, suggesting that the descriptive perspective shows us that we need a different notion of expression from the one the instrumental perspective offers. I will begin by articulating the instrumental perspective as I find it in Green's book Self-Expression, and then articulate the challenge against this perspective. Then I will turn to developing the descriptive perspective. In the final section I will make some clarifications and develop the challenge further by looking at how Green attempts to make space for a constitutive link between expressions and mental states.

\section{Expression as signaling: Green's instrumental perspective}

The opening sentences of Green's Self-Expression reads:

We express ourselves in many ways: through tone of voice, posture, the face, words, and in more subtle cases, paint, music and other forms of art. Linking these disparate phenomena together is a pattern of behavior coping with a felt need. (Green 2007, 1)

The passage begins with recalling a familiar fact. We, human beings, have a vast range of ways of expressing ourselves, from facial expressions, to novels, songs, and paintings. Having called our attention to this delightful fact, Green immediately suggests a way of initially characterizing all these forms of expression, of bringing them together under a common description. They are all, Green suggests, patterns of behavior coping with a felt need. This need, he elaborates, is the need to "manifest our point of view" (Green 2007, 1). 
If the first sentence of the quoted passage is theoretically innocuous, a simple reminder of an undeniable fact, the second sentence already takes up a certain theoretical perspective on this fact. This is a theoretical perspective that Green holds on to and elaborates throughout his book. There we see expression described as a means, an instrument for a specific purpose. We have a felt need, to make our point of view manifest, and we have a way (or ways) of satisfying this need, namely expression. As we shall see, Green's elaborated theory of expression does not assert that expression always has to involve a felt need. Rather, we can see these first sentences as setting up a question: What can it mean to view expression in instrumental terms? How can we elaborate the idea that expression serves the purpose of making our point of view manifest to others?

One very important step for Green in making good on this task is the idea that self-expression is a signal (Green 2007, 26). This thesis appears in a list of twenty theses, which Green calls 'dicta'. Green does not tell us much about the choice to call his theses 'dicta'. According to the dictionary, a dictum is a pronouncement, or a formulation of general principles or truths. Green's twenty dicta function in both ways - they both declare how Green is going to use his terms and what he will take for granted, and assert what he takes to be the basic truths and principles governing the area he will be investigating. This particular dictum: self-expression is a signal, is one that directly responds to the question of what, according to Green, it means to view expression in instrumental terms.

Green gets the notion of a signal from evolutionary theories of communication. A signal is a sign designed for the purpose of communication. Green's notion of design is capacious, and this capaciousness is also the key to how he can hold on both to the idea of expression as an instrument, and to the idea that we as individuals do not always and everywhere express ourselves because we feel a need to relay information about our mental states. In Green's theory design spans an evolutionary process, an intentional process at the level of individuals, and an intentional process at the level of a social community (Green 2007, 5, 137-151). Expressions can be naturally selected for their capacity to transmit information. Expressions can also be selected by individuals in an effort to get one's point of view across (or perhaps be selected by a sort of happenstance). And expression 
can, finally, be selected by a process of conventionalization at the level of society. If an expression is naturally or conventionally designed, its instrumentality need not be a matter of an individual using it for a specific purpose.

The idea that expression is a means of coping with a felt need thus gets broken down into different more specific notions of instrumentality, with more or less clear connections to what one naturally thinks of as "coping with a felt need". To evince a signal that evolution or society has selected for its capacity to transmit information about mental states need, conceptually or experientially, have nothing to do with feeling a need to make anything manifest. (There is a legitimate worry here that that the three notions of design are so disparate in meaning that Green's theory cannot vindicate our sense that he is articulating a unity that can be captured in one definition. But I will leave that worry to the side. $)^{6}$

What I want to focus on now is the idea that expression is a matter of using or evincing already established means of communication, or else setting up a new connection between a state of mind and a piece of behavior. I will now articulate a challenge for Green's instrumental perspective by discussing the consequences of his theory for our understanding of a particular example, an example I take from Green's book.

Green uses a range of quite lovely examples from literature, in particular great novels of the $19^{\text {th }}$ century. In the specific example on which I want to focus, we find Rosamond Vincy from George Eliot's Middlemarch. For texture, I render the entire passage from the novel also quoted by Green:

This was not an infrequent procedure with Mr Vincy - to be rash in jovial assent, and on becoming subsequently conscious that he had been rash, to employ others in making the offensive retractation. However, Mrs. Vincy, who never willingly opposed her

\footnotetext{
${ }_{6}$ The title of Green's book is not merely Expression but Self-Expression. This might lead us to think that Green's topic is the romanticist concern with expressing one's authentic self. Green does not, however, focus much on the self. Self-expression for Green has to do with expressing one's own states of mind, which is linked to the "introspectibility" of what can be self-expressed. He distinguishes self-expression from "expressiveness", which can be a property of inanimate objects, such as a when a "windswept cliff might look melancholy" (Green 2007, 38-41).
} 
husband, lost no time the next morning in letting Rosamond know what he had said. Rosamond, examining some muslin-work, listened in silence, and at the end gave a certain turn of her graceful neck, of which only long experience could teach you that it meant perfect obstinacy. Eliot, 2000 [1874], 214.

In discussing Rosamond's turn of the neck, Green argues on the basis of the theory he proposes that it is not clear whether she is here expressing her obstinacy or not. Green says about Rosamond that her twist of the neck might not be a signal (and hence not an expression) since "it is not clear that she twists her neck for the purpose of showing determination, or for the sake of making as if to act on that determination." One way for it to become a signal, Green continues, is if she begins to "consciously to twist her neck for the purpose of displaying this 'perfect obstinacy.' If she does so, she may also be expressing her determination (Green 2007, 143)." Perhaps there are also less conscious and deliberate ways for Rosamond's twist of the neck to become a signal. If we understand the notion of individual design as capaciously as possible but still compatible with Green's theory, we can expand the space of possibilities here and say that her neck-twist might become a signal also by a sort of non-deliberate happenstance. She simply starts doing to twist her neck regularly when she is feeling obstinate, and it thus comes to be designed to convey her obstinacy. ${ }^{7}$

Green uses this example to clarify certain aspects of his theory. He never considers the thought that it might be a counterexample. That is, he doesn't consider the possibility that the example might describe a form of expression that does not fit his theory. I will now describe and develop the example in a way where it sits uncomfortably with Green's core dictum that selfexpression is a signal. On this elaboration of the example, Rosamond Vincy

7 When Green initially describes what design by individuals amounts to he describes it as the "work of an intelligent agent", and as having to do with "the choice of an intelligent, conscious agent" $(2007,5)$. This suggested to me that his model of individual design is an individual deciding consciously to use a form of behavior to convey a particular state of mind. In conversation, Green told me that he wants to leave it open that individual design also can be a form of happenstance. One might, without conscious intention, happen upon a form of behavior that then comes by regularity to be (for others) associated with the state of mind in question. 
did not wish to display her obstinacy by twisting her neck, nor has previously by a sort of happenstance come to twist her neck regularly when she is feeling obstinate. Neither is, we might suppose, this neck-twist a conventionalized mark of determination for her society or social-group. Nor a naturally selected piece of behavior. In fact, Rosamond's obstinacy was, when she twisted her neck, not quite clear even to herself, but gradually, and in the process of her expressing it in her posture, became clear to her (and to others). She embodied her obstinacy, in a way not determined either by her intention or by previously established relations of information-bearing or representation. Her obstinacy was not only made available to others when she expressed it, but took form as she expressed it. Her obstinacy was not a previously existing phenomenon, it took shape in her novel expression of it. $^{8}$

Green takes the case of Rosamond Vincy to have the potential to show us that there is room for individual variation in his theory of expression. There is space, he wants to show, for those who "express themselves in ways that do not conform to universal or near-universal patterns" (143). What is still the case, however, is that those non-standard (in the sense of nonuniversal) types of behavior need to be designed to convey what they do, in order to count as expressions on Green's view. This means that Rosamond, on the reading of the example I just gave, cannot be (on Green's theory) expressing her obstinacy in her neck-twist. For how can the necktwist have been designed to convey Rosamond's obstinacy, if the obstinacy did not exist in any robust sense before it was embodied in the novel expression of a slight turn of the neck?

Say that Green now would respond to this question by saying that he requires something quite minimal for a piece of behavior to count as designed in the relevant sense. Say he argues that all that is required is that the piece of behavior that expresses in a novel way the non-hitherto existing state of mind is that it is intelligible by (some select group of) others as carrying information about that state of mind. Then Green would be able

8 This reading of the example might appear precluded by the fact Eliot writes that only long experience could teach you that the twist of the neck meant perfect obstinacy. I think that "long experience" could here mean simply long experience with Rosamond, i.e., knowing her well. 
to accommodate my elaboration of the example as a genuine case of expression. However, this response would effectively do away with design and explain signaling in terms of a prior notion of the intelligibility of an expression. It would not be possible to cash out the intelligibility of the expression in terms of the piece of behavior being selected to convey that state of mind. The intelligibility of the expression is rather what explains why it is selected.

Hence I see the Rosamond Vincy case as posing a dilemma for Green's theory. Either he denies that the description I gave of the case (where the state of mind took shape in a new form of expression of it) captures a genuine case of expression, or he gives up on the core claim of his theory, that expression is signaling. We might wonder what would be so pernicious about denying that a state of mind can take shape in an original form of expression. As I see it, there are two problems with this.

The first is that it appears, as a matter of everyday experience, to happen all the time. My mixture of confusion and sadness in the face of one of Trump's latest tweets can take the form of a crooked smile and a humming of the tune "My way", through which it materializes that my confusion and sadness has to do with how a certain kind of gonzo self-assertiveness can be a route to actual devastating power. I might not have any such thought before I started smiling and humming, the response was directly elicited by the tweet itself. And by no stretch was the humming and smiling designed in Green's sense to convey the information that I am sad and confused about the devastating power of gonzo masculinity.

The second problem is that denying true expressive inventiveness makes it difficult to understand how new thoughts and reactions could ever be possible. It seems as if all each subject can do in terms of expression is to make use of already existing relations of information-carrying. For a subject to consciously to start to use some piece of behavior to convey a particular state of mind, the state of mind needs to be clear enough to the subject, in which case we are presupposing that the subject has access to some way of expressing it (even just to herself). If we allow selection by happenstance, this requires a regular connection, in which case we are again presupposing that there is a mental state with some determinate content that can stand in this relation of regularity. Again the expressive articulation of genuinely new mental states appears precluded. In so far as we think that the 
possibility of new thoughts and responses is an aspect of subjectivity, then we have lost something quite important. ${ }^{9}$

One response to this argument on behalf of the instrumental perspective could be to say that the sort of case I imagined through a new reading of the Rosamond Vincy case, should in fact be called something else, and be accounted for as a separate topic. Not all manifestations of mental states are expressions, and those that aren't designed are real enough, but they aren't expressions, this response would go. What this response would concede, would then be that expression as signaling presupposes a form of embodiment of mental states that it cannot account for, but that also has the capacity to make the subjective point of view of others intelligible. If so then the theory appears to be less interesting than advertized.

I have argued that the Rosamond Vincy case can be read as a counterexample to Green's theory, if we read it as presenting us with a case of a state of mind taking shape in a new form of expression. Green's notion of expression as signaling cannot accommodate such a case, I claimed. I also argued that there is something important at stake in preserving a space for expression in which a state of mind takes shape in a new form of expression, namely the possibility of genuinely new thoughts and responses.

The possibility I have wanted to make room for, is of central importance to Merleau-Ponty, who is one of the two thinkers I am drawing on in articulating the descriptive perspective. In the quote I used as an epigraph to this paper, we see Merleau-Ponty describing speech as a gesture that breaks a primordial silence. In the passage from which this quote is taken, MerleauPonty discusses how expression as the formation of significance is easily neglected when we reflect on expression. Precisely because we reflect from

9 We might wonder here whether the argument about expressive inventiveness and variation has any bearing on non-human animal expression. Although I think there is reason to distinguish expressive variability in non-human animals and expressive variability in human beings, I think expressive variability as such also characterizes non-human expression. Although I would not agree with Alice Crary that "individual animals exhibit the same sort of natural expressive variability that human beings to" (Crary 2016, 78, my emphasis), I would agree with her that animals exhibit expressive variability. See my "'Modes of a complicated form of life': Expression and HumanAnimal Continuity" for a discussion of this point (Bäckström 2018).

Organon F 28 (2) 2021: 282-302 
within a world where we are already thinking and speaking, we tend to think that all expression is a mere peddling of already formed significations. Such significations, Merleau-Ponty argues, "assumes that the decisive step of expression has been accomplished". There must be expression that "breaks a primordial silence"-i.e. expression that involves the formation of significance, both for the subject who is doing the expressing and for the (possible) other who understands it (Merleau-Ponty, 2012 [1945], 189-190).

I read Merleau-Ponty as arguing that instrumental expression is there alright, but it is not the most fundamental or paradigmatic case of expression. The more fundamental case is a new expression, where there is at the same time a new significance formed for the subject and for the (potential) other. I now want to turn to explaining how this specific thesis forms a part of the descriptive perspective on expression.

\section{The descriptive perspective: Merleau-Ponty and Wittgenstein}

According to the descriptive perspective, we need a different notion of expression than the instrumental one precisely to describe how the world can come to take on significance for a subject; how she can come to make sense of the world. If we think back to the example with Rosamond Vincy, Merleau-Ponty would urge us to see her gesture as taking her from silence to noise (metaphorically speaking in this case since her gesture is not an audible one), from a situation as of yet decoded and formulated to a situation that has taken on a particular significance for her. To think of expression as something that breaks a primordial silence is to take it to create something that wasn't present before. To break a silence in this sense is not to take some aspect of one's subjective point of view and demonstrate it to others, it is for one's subjective point of view to take some particular shape.

Earlier, I characterized the descriptive perspective as interested not merely in what an expression is, but also and perhaps primarily in the mode of being of an expression. I went on to say that the descriptive perspective takes the question of what it is for an expression to be as inseparable from the question what it is for mental states to be. The idea of a new expression 
as I have explained it using Merleau-Ponty begins to give content to what this might mean. In such an expression the state of mind and its embodiment or manifestation are not distinct phenomena. Indeed, Merleau-Ponty would argue that the language of "state of mind" and "manifestation" is misleading in that it suggests that the state of mind has a kind of descriptive priority, it suggests that the "state of mind" is an independently intelligible something, quite apart from its "manifestations".

In a sense, Merleau-Ponty's entire project in Phenomenology of Perception can be seen as an attempt to establish a different and less misleading vocabulary for describing expression, than the one of "manifestation of a mental state". In the course of this project Merleau-Ponty argues that speech (which on his view is continuous with gestures and non-verbal forms of expression) is an "originating realm" (202). Negatively, this means that speech is not the "external sign" of an "internal recognition". Language is not the "external accompaniment of thought" (205). Positively, it means that speech, or expression, more generally, achieves or accomplishes thought (or other mental states, such as emotions). Thus, for MerleauPonty, expression (in one important sense) is not a matter of manifesting inner content, but a matter of accomplishing content (which he would neither call 'inner' nor 'outer').

Merleau-Ponty does not argue that all cases of speech or non-verbal expression are originating in this sense. In a footnote he clarifies that what he says applies to "first-hand" speech, examples of which are a child saying her first words, a lover revealing her feelings, or a philosopher "who reawakens primordial experience" (208, footnote 5). Second-order expression, which he calls speech-about-speech, "makes up the general run of empirical language" (207, footnote 4). Thus, Merleau-Ponty's argument is not that all or even most we say or otherwise express is aptly described as the formation of significance or as expression in the primary sense. Rather, the point is that alongside speech that merely repeats already formed significances (second-order-speech), there must also be the phenomenon of significance accomplished or formed in expression in the primary sense. ${ }^{10}$

10 Baz (2017) articulates a similar point: "Part of what Merleau-Ponty is trying to get us to see is that we are not confined to the impersonal way of seeing things: 
I said above that the descriptive perspective is interested in the mode of being of an expression, and eo ipso in the mode of being of mental states. Now, what does this mean, and what does it have to do with my reading of the Rosamond Vincy case and Merleau-Ponty's primordial gesture? If we think back to the description that initiated Green's inquiry, expression as coping with a felt need to manifest one's mental states, we can say that Merleau-Ponty's primordial gesture (Rosamond's twist of the neck) tells us something about what it means to have mental states. If expression is a sort of thing in which someone's obstinacy not merely is manifested but comes to be, we need to bring in expression right in our description of what mental states are. And doing so will entail putting into relief and questioning mental states as something we simply "have". Perhaps "having" them is rather different from the "having" of other sorts of things.

I see the later Wittgenstein as sharing Merleau-Ponty's concern with questioning, through an interest in expression, what it is to have mental states. In The Philosophical Investigations, this concern is brought to the fore in a series of paragraphs starting at roughly $\S 281$, where Wittgenstein approaches from different angles the question of what is for pain to be. We talk about pain as something we have in parts of our bodies, but if we consider these forms of talk too much in isolation from the rest of our use of the concept of pain, we risk understanding having pain as having an object, such as having a broken bone in one's foot, or possessing an attribute, such as having black hair. In $\S 302$, he turns to the question what it is to imagine someone else's pain. Whatever this means, it can't mean, he claims, to "make a transition from one place of pain to another". What this would amount to is to imagine oneself feeling pain in some region of someone else's body. He concludes this paragraph by saying, "Pain-behavior may

though we must always rely on an inherited background of impersonal meanings[...] there is always the possibility of seeing things more or less creatively, differently, personally. [...] Consider how even the most basic biological states and functionshunger, thirst, eating, drinking, being hot or cold, needing and seeking shelter, experiencing sexual desire, satisfying it, and so on - have come to mean for us so much more than whatever they might be thought to mean 'purely biologically'; and consider also how each one of those states and functions may still be given a more or less new and personal meaning by an individual[.] (350)" 
point to a painful place, but the subject of pain is the person who gives it expression." (Wittgenstein, 2001, [1953], §302) If you want to say that pain is a possession or an attribute, Wittgenstein argues here, remember that it is something a subject expresses. A subject does not express her broken bone, or her black hair. To express something isn't merely or primarily to describe or ascribe it to oneself, nor is it to show or point to something. Such language retains the idea that there is something, a primary reality, that the expression describes, points to, or shows. An expressive movement, rather, can be a movement of becoming, where that which is expressed is completed and shaped in its expression. ${ }^{11}$

What unites Wittgenstein and Merleau-Ponty here is the idea that our thinking about the mind and the body has a tendency to proceed in neglect of the fact that we are subjects of expression. This often takes the form of levelling important distinctions between having a living body and having other "possessions". Wittgenstein highlights that when we talk about pain located in a part of the body, the body is not here an object in the same sense as, say, a stone is an object. He engages in a thought-experiment:

Couldn't I imagine having frightful pains and turning to stone while they lasted? Well, how do I know, if I shut my eyes, whether I have not turned into a stone? And if that happened, in what sense will the stone have the pains? In what sense will they be ascribable to the stone? And why need the pain have a bearer at all here?!

And can one say of the stone that it has a soul and that is what has the pain? What has a soul, or pain, to do with a stone?

Only of what behaves like a human being can one say that it has pains. (Wittgenstein 2001 [1953], §283)

11 My understanding of expression, in particular in relation to Wittgenstein, is heavily indebted to the work of David Finkelstein. In his book Expression and the Inner (2003), Finkelstein argues that pain and its expression "make sense together in something like the way that two parts of a single sentence do" (135). This metaphor pulls us in the direction of thinking of expression as precisely something which finishes or accomplishes a unity of significance, not as something which indicates or points to something already completely determinate and fixed.

Organon F 28 (2) 2021: 282-302 
We might think that this last comment shows us that Wittgenstein is skeptical about attributing pain to other animals than human beings. But this is not what he means with the phrase "behaves like a human being". He might have said, instead: only of an expressive creature can we say that it has pains. Pain belongs in the life of an expressive animal. ${ }^{12}$ This becomes clear in the paragraph immediately following the previous. There he compares attributing pain to a stone to attributing it to a number. But, he says, "look at a wriggling fly and at once these difficulties vanish and pain seems to be able to get a foothold here, where before everything was, so to speak, too smooth for it (\$284)."

A stone or a number is not an expressive body, whereas a fly is, or is at least a limiting case of one. An expressive body is one about which our concept of pain gets a foothold. This means that for Wittgenstein, while expression can be an instrument of communicating this or that specific pain, or this or that specific desire, it is also and importantly the mark of a conceptual (grammatical, categorical) difference: it indicates a qualitative break. Paragraph 284 continues:

And so, too, a corpse seems to us quite inaccessible to pain.--Our attitude to what is alive and what is dead, is not the same, All our reactions are different.---If anyone says: "That cannot simply come from the fact that a living thing moves about in such-and-such a way and a dead one not", then I want to intimate to him that this is a case of the transition "from quantity to quality'. (284)

The final sentence of this paragraph is, I think, Wittgenstein's attempt to find a language for what Merleau-Ponty describes as the "gesture that breaks the primordial silence". In the previous section I explained MerleauPonty's idea in terms of a new expression, a mental state coming to take shape in a novel expression. But we might understand the idea of a primordial silence as also indicating how expression is descriptively distinct from other forms of movement. A living thing does move about in such-and-such ways, where a non-living thing might move about in different ways (a stone

12 Here again I am indebted to Finkelstein who says that, "a pain and its expression hang together in the logical space of animate life" (2003: 135). 
might fall or roll, for instance). But "move about" then is a phrase covering up a qualitative difference, a radical break. An expressive movement is preceded by silence, in the sense that its mode of being is different from the mode of being of something dead, non-expressive.

In the introduction I mentioned that Green also wants to articulate a constitutive connection between expressions and mental states. In distinction with Wittgenstein and Merleau-Ponty, however, he does not think articulating this constitutive connection requires us to be suspicious of using language to describe this relation taken from the domain of mere physical objects. If we look at the analogies Green uses to describe how expressions are bound up with mental states, it will be easier to see how his perspective differs from the descriptive. This will also allow me to re-state the challenge I posed in the previous section, but from a different angle.

\section{Apples, galaxies, and emotions}

I have argued that we need space for cases where mental states take shape in novel forms of expression, and that doing so requires us to think about what it is for expressions and mental states to be. Now, Green also thinks that there are constitutive links between mental states and their expressions. This is not a required aspect of the instrumental perspective as I have articulated it, but it is a thought Green wants to make space for. This in turn has to do with the fact that Green wants room for the possibility of directly perceiving other people's mental states rather than inferring them from their behavior. (He shares this ambition of making space for perceiving rather than inferring mental states with both Merleau-Ponty and Wittgenstein.) In Green's theory, expressions are described as (at least sometimes) characteristic components of mental states (Green 2007, 88-93). Green's primary example in this regard is emotions. Emotions are such as to include (at least some of) their signals as parts, he argues. When one perceives an expression of emotion that is a characteristic component of the emotion, one eo ipso perceives the emotion itself.

Now, at first blush this is a difficult thought to wrap one's head around. The idea of a signal starts to look oddly self-referential: a signal is designed to convey information about a mental state of which itself is a part. For 
this idea to be less mind-boggling, we need to think of the signal-part or aspect of the emotion as having some relatively robust criteria of identification that sets it apart from "the rest" of the emotion (which the signalpart is designed to convey). It is, after all, not particularly mind-boggling to think about a sweater as a composite whole that includes the tag designed to convey information about its properties.

When we try to think about what this part/whole relation could mean in the case of emotions and their expressions, however, we encounter difficulties. There is the part of the emotion we perceive, but there are also the unperceived parts of the emotion. These unperceived parts of the emotion now look out of reach in a worrisome way. The label on the sweater mentions properties (such as what material it is made of) that we are familiar with and understand in other ways than reading about them on clothing tags. But the properties the signal makes us privy to are not, or at least not obviously, such that we could be familiar with them in other ways than through the signals. We are left with only the tags, as it were, and this strikes us as problematic and disappointing situation.

Green wants to articulate what sort of part/whole relation he envisages by using two analogies, first with apples and then with galaxies.

Someone who presents to me an apple from one angle has thereby shown me an apple even if I do not inspect its interior or its other side. The reason is that a sufficiently large portion of a side of an apple is, for normal human observers, not only itself perceptible but also a characteristic component of the apple. (Green 2007, 86)

Now, an apple can of course be turned around, in which case its other side would appear to perception. Apples are not such that their back sides are perpetually hidden from view. But what about the other components of states of mind? Green responds to this worry with a new analogy: galaxies. He concedes that we cannot see all parts of an emotion, but that this is in fact not peculiar to the case of emotions. We can see galaxies, Green argues, even when we cannot in principle perceive the black hole in their middle (Green 2007, 89). Hence, there are perceptible objects with parts in principle hidden from view. Emotions are akin to, Green, suggests, such perceptible objects. 
From the perspectives of Merleau-Ponty and Wittgenstein, these analogies raise more descriptive and epistemological questions than they answer. The first idea, that of an expression as the "facing side" of an emotion, pushes us in the direction of thinking of that there must be another perceptual vantage point on the emotion, or some way of making the non-facing side appear. When we then realize that there doesn't seem to be any such vantage-point (apart from, perhaps, the one of the subject herself) we are thrown upon worries about how we could know anything about the properties of the non-facing side. The second analogy, where emotions are galaxylike complex objects with invisible centers, leaves us wondering where we would get the idea of such an emotional center. Galaxies and black-holes are objects of natural-scientific understanding and theorizing. But it is less clear by virtue of what theory-like construction we would get any robust idea of the invisible emotional center of a complex mental state.

For Wittgenstein and Merleau-Ponty both, expression requires us to look with suspicion on an attempt to assimilate mental states to physical objects. But a notion of expression that is antecedently conceived of in instrumental terms will not be of any use in this respect, they would argue. When Green includes signals as characteristic components of emotions, he then (they would say) effectively tacks signals onto something we have been given scarce resources to understand. From the perspective of Wittgenstein and Merleau-Ponty, Green misses the chance to let the notion of expression open for an understanding of the mode of being of expressions and, thereby, of mental states.

\section{Concluding remarks}

My aim in this paper was to formulate a challenge to Green's thesis that an expression is a signal, by developing a contrast between two perspectives on expression, the instrumental and the descriptive. It might seem as if I in the end articulated two distinct challenges. The first challenge would be how the instrumental perspective can make space for mental states to take shape in new forms of expression. The second would be whether the instrumental perspective has the resources to help us understand the mode of being of mental states and expressions. In fact, I take these challenges to 
be one and the same. For making space for the possibility of the formation of significance through new expressions means acknowledging that at least in such a case we need to understand the relation between the mental state and the expression in terms, to borrow Merleau-Ponty's words, of the expression accomplishing or achieving the mental state. This way of putting the link is in sharp tension with the idea that the expression is one part of some complex whole whose other part (the mental state itself one is tempted to say) has some intelligibility apart from its expression. Hence, if we are to understand Merleau-Ponty's primordial gesture, we need a constitutive link that cannot be captured in the terms offered to us by the instrumental perspective.

\section{Acknowledgments}

I owe thanks to Mitchell S. Green, Martin Gustafsson, Eva Schwarz, Fredrik Svenaeus, and an anonymous reviewer for comments on previous versions of this paper.

\section{References}

Baz, Avner. 2017. "Motivational Indeterminacy." European Journal of Philosophy 25 (2): 336-57. https://doi.org/10.1111/ejop.12163

Bäckström, Stina. 2013a. "Our Relation to Our Own Expressions: Comment on Bar-On, Green, and Finkelstein." Analytic Philosophy 4/54: 466-76. https://doi.org/10.1111/phib.12029

Bäckström, Stina. 2013b. "Seeing People and Knowing You: Perception, Shared Knowledge, and Acknowledgment." European Journal for Philosophy of Religion 5/4: 55-73. https://doi.org/10.24204/ejpr.v5i4.205

Bäckström, Stina. 2016. "Expression and Self-Consciousness." Philosophical Topics 44 (1): 161-80. https://doi.org/10.5840/philtopics201644110

Bäckström, Stina. 2018. "'Modes of a Complicated Form of Life': Expression and Human-Animal Continuity". In Wittgenstein and Naturalism, edited by Kevin Cahill and Thomas Raleigh, 223-40. London and New York: Routledge. https://doi.org/10.4324/9781315301594

Crary, Alice. 2016. Inside Ethics: On the Demands of Moral Thought. Cambridge, Mass. and London: Harvard University Press.

https://doi.org/10.4159/9780674089075

Eliot, George. 2000 [1871-72]. Middlemarch. New York and London: W.W. Norton and Company. 
Finkelstein, David H. 2003. Expression and the Inner. Cambridge, Mass. and London: Harvard University Press.

Green, Mitchell. 2007. Self-Expression. Oxford: Oxford University Press. https://doi.org/10.1093/acprof:oso/9780199283781.001.0001

Kuusela, Oskari, Mihan Ometiță, and Timur Uçan, eds. 2018. Wittgenstein and Phenomenology. London and New York: Routledge. https://doi.org/10.4324/9781315626307

Merleau-Ponty, Maurice. 2012 [1945]. Phenomenology of Perception, translated by D.A. Landes. London and New York: Routledge. https://doi.org/10.4324/9780203981139

Romdenh-Romluc, Komarine, ed. 2017. Wittgenstein and Merleau-Ponty. London and New York: Routledge.

Wittgenstein, Ludwig. 2001 [1953]. Philosophical Investigations, third ed., translated by G. E. M. Anscombe. Oxford: Blackwell Publishing. 